\title{
La política exterior chilena y América del Sur
}

\author{
Ángel Flisfisch*
}

\section{A. Complejidades y ASIMETRÍAS.}

De todos los ámbitos en que ha tenido que desplegarse la política exterior chilena, probablemente el suramericano es el que ha planteado mayores dificultades. Ello explica que pese a que el carácter de las condiciones iniciales que determinan el desarrollo nacional apuntaban a ese ámbito como el dominio privilegiado para el despliegue de esa política, su emergencia como una política en forma sea un fenómeno muy tardío, susceptible de datarse a partir de las últimas cinco décadas, y adicionalmente en términos de una trayectoria afectada por severas discontinuidades y provista de una cabal irregularidad. En efecto, el ámbito suramericano desde el inicio trasciende la sola geografía: la localización espacial, unida a la cultura,

* Abogado y politólogo, ex Director de FLACSO Chile la historia, la lengua y los componentes étnicos mayoritarios presentes configuran cabalmente una comunidad de origen, ciertamente ausente, por ejemplo, en el caso de los países que hoy integran la Unión Europea. No obstante, más que la emergencia y desarrollo de una política, puede decirse que lo que se ha presenciado es una sucesión de políticas distintas, cuya aparición es precedida por importantes intervalos en que lo que se tiene son períodos vacíos de políticas, y esto es válido para todos los países que componen la región. La consecuencia natural de este orden de cosas han sido, por una parte, episodios de frustración severa de expectativas, y una permanente perplejidad frente al contraste entre el carácter favorable de las condiciones originales ya referidas y la incapacidad generalizada de construir una comunidad de destino a partir de una clara comunidad de origen. Por la otra, un extendido escepticismo sobre 
los futuros posibles de Suramérica como una configuración geopolítica y geoeconómica relativamente cohesionada.

Ciertamente, una política exterior cuyo referente u objeto sea Suramérica no tiene por qué ser necesariamente una política cuyos objetivos sean objetivos de integración. De hecho, una política exterior hacia una región puede tener como objetivos precisamente la obstaculización de procesos de integración. Por ejemplo, hay propuestas de política exterior europea en Francia o en Inglaterra que parten de la premisa de que lo deseable es justamente no pertenecer a la Unión Europea. O bien, puede tratarse de otros objetivos, ajenos a procesos de integración o cooperación regional. Lo que importa es que se trate de una política cuyo referente u objeto sea la región, en este caso, América del Sur. Lo afirmado anteriormente es válido para el caso general y la perplejidad permanece, puesto que el peso específico del contexto geográfico inicial, físico y humano, y del contexto histórico están igualmente presentes trátese o no de iniciativas con connotaciones integradoras y cooperativas.

Se han avanzado varias explicaciones sobre este estado de cosas que ha prevalecido durante casi doscientos años. Por ejemplo, se argumenta que parte importante de la herencia colonial consistió en una división territorial caracterizada por fronteras difusas, lo que implicó procesos posteriores de consolidación nacional en los que alcanzó un énfasis más que prioritario la delimitación precisa de fronteras como condición de un ejercicio efec- tivo de soberanía, con la consiguiente proliferación de conflictos bilaterales (guerras de frontera, modificaciones territoriales, disputas geográficas), que arrojan largas sombras hasta hoy (Fernández, 2010). Ello da también cuenta de la preeminencia -casi hegemonía podría decirse- de las relaciones vecinales y las cuestiones asociadas a ellas como característica permanente de las agendas de la política exterior de los países suramericanos.

Ese rasgo permanente de las agendas solo tiende a variar en el caso de Chile en las últimas dos décadas, y es necesario subrayar que la disputa efectiva por prioridades y por consiguiente la mayor diversificación de la agenda viene dada fundamentalmente por la emergencia de temas multilaterales, de acentos en relaciones comerciales internacionales y políticas hacia países y bloques fuera de Suramérica, más que por la relevancia efectiva otorgada a una política suramericana. Ello se observa con claridad, por ejemplo, en un documento oficial de la Cancillería chilena, Principios y Prioridades de la Política Exterior de Chile, del año 2007 (Gobierno de Chile, Ministerio de Relaciones Exteriores, 2007), en el cual, sin perjuicio de la presencia de elementos retóricos respecto de la consabida prioridad puesta en América Latina, tema sobre el que se volverá más adelante, Suramérica ocupa solo un recuadro de algo más de media página en un total de 83 páginas, referido de manera específica a la Unión de Naciones Suramericanas (UNASUR), aun cuando la agenda que perfila el do- 
cumento es muy diversificada, sin que sea patente una prioridad excluyente otorgada a temas vecinales.

El mismo autor antes citado (Fernández, 2010), en el contexto de las posibilidades de procesos de integración tanto en América Latina como en Suramérica, avanza otros dos argumentos que también pueden explicar la ausencia de políticas hacia esa segunda región.

Primero, como consecuencia de la política colonial de comercio borbónica, los países suramericanos se caracterizaron, durante un muy largo período, por modalidades de inserción en la economía mundial que privilegiaron la mono-producción de materias primas y su exportación a los países centrales, con relaciones de intercambio comercial sumamente débiles entre ellos mismos. Aun cuando el autor no lo señala, hay que entender que algo muy similar sucedió con Brasil. Por consiguiente, hasta las dos o tres últimas décadas en el contexto suramericano estuvo ausente ese poderoso incentivo que habría constituido la existencia de un mercado suramericano económicamente relevante, o al menos de mercados subregionales importantes. De haberse dado esas condiciones, habría sido difícil para Chile y los restantes países sustraerse a la necesidad de contar con una política exterior orientada a las región, sea con objetivos de integración u otros distintos y posiblemente aun contradictorios con metas de integración.

Segundo, debe considerarse que los nuevos Estados suramericanos se desarrollan políticamente a partir de componentes militaristas y caudillistas más que significativos, con contenidos nacionalistas cuyo sentido viene dado y reforzado principalmente por los conflictos de frontera, que se convierten así en factores de cohesión interna y en recursos consagrados de la política interna. Nuevamente los incentivos operarían en contra de un referente regional como el objeto visiblemente relevante para una política exterior, relegado a rincones más que secundarios de los focos de atención por la urgencia inmediata de las cuestiones vecinales.

Parece más que plausible que los fenómenos indicados han hecho contribuciones importantes al déficit de que aquí se trata. No obstante, hay razones para pensar que ellos no tendrían por qué haber llevado necesariamente a ese déficit. Por ejemplo, las cuestiones limítrofes contenciosas no estuvieron precisamente ausentes de la historia de la Europa decimonónica y ello no impidió que Francia, el Reino Unido o la Alemania Guillermina pusieran una alta prioridad en contar con una política europea. De la misma manera, es un período de la historia europea más que fuertemente determinado por los nacionalismos, que no operaron en la dirección de tornar irrelevante para los actores de esa historia el contar con una política europea sino todo lo contrario. Por otra parte, si bien la economía mundial significativamente globalizada existente hasta 1914 se derrumbó estrepitosamente y la sucedió un contexto caracterizado por fuertes tendencias autárquicas, ello tampoco fue obstáculo 
para la emergencia y desarrollo de políticas europeas, incluyendo la política aislacionista estadounidense, un claro ejemplo sobre cómo una política exterior con un referente regional global puede tener objetivos explícitos hostiles a la cooperación y la integración.

En realidad, además de los elementos ya esbozados, que quizás no llevaban necesariamente a una ausencia de políticas regionales, hay una característica esencial de la configuración geopolítica histórica de la región que contribuye principalmente a dar cuenta de ese déficit que aquí ocupa. A la vez, su identificación permite explicarlo como producto no de torpezas, miopías irracionales o patologías culturales sino justamente al contrario, de comportamientos «razonablemente» racionales.

Nuevamente, la comparación con Europa posibilita hacer claridad sobre la hipótesis que aquí se va a avanzar. Como es bien sabido, desde la consolidación de los Estados absolutistas, y quizás aun desde antes, el occidente europeo, incluyendo el imperio zarista, se configuró en términos de un relativo equilibrio, pese a la existencia de asimetrías no menores. Ese rasgo, claramente histórico en el sentido de una larga duración, se mantiene hasta hoy. De hecho, parece difícil prescindir de él y no considerarlo como una condición necesaria para el éxito del proceso de integración que se ha desarrollado durante las últimas seis a cinco décadas. $\mathrm{Al}$ menos cuatro o cinco de los principales actores guardan entre sí pesos aproximadamente equivalentes, y ello abre espacios de posibilidades coaliciónales para los actores de menor peso relativo. En esas condiciones, contar con políticas con referentes regionales es algo que viene impuesto por la fuerza de las circunstancias: no es racional ignorar a ningún actor, puesto que en los juegos entre Estados ninguno de ellos es «prescindible» ${ }^{1}$.

Ciertamente, América del Sur presenta un cuadro muy diferente. Dentro del conjunto, el peso de uno de los países, Brasil, supera con creces al de cada uno de los restantes considerados aisladamente, y es difícil concebir coaliciones que puedan erguirse en condiciones razonablemente igualitarias con Brasil, incluyendo algo así como una coalición de «todos contra uno», igualmente difícil de imaginar. Adicionalmente, vale la pena destacar que la asimetría entre Brasil y el resto se reforzó durante las últimas tres décadas: Brasil creció del $34 \%$ al $56 \%$ del PGB sudamericano, en un contexto en que solo el Perú y Chile crecieron algo más de un $1 \%$, y en que países como Argentina bajaron del $27 \%$ al $11 \%$. Ello no agota el cuadro de las asimetrías presentes en la región. Hay siete casos que si bien podrían clasificarse como países medianos, guardan entre sí distancias importantes. Todo

\footnotetext{
Desde el punto de vista del éxito del proceso de integración contemporáneo ese rasgo del contexto histórico geopolítico aparece como algo positivo, virtuoso. Sin embargo, es probable que también se vincule a cinco siglos de destrucción y muerte, que superan, en términos de barbarie e inhumanidad la historia paralela de Suramérica.
} 
ello considerando elementos que cabría denominar de estructurales, constantes en períodos largos. Contemporáneamente, esa heterogeneidad se magnifica por la presencia de otros elementos que se examinarán más adelante.

Bajo esas condiciones, salvo el caso de Brasil, para cualquiera de los actores proponerse la meta de identificar e implementar autónomamente una política cuyo referente u objeto es la región es perfectamente irracional desde un punto de vista instrumental, siempre que exista sinceridad en cuanto a ese referente y no se trate solo de una operación demagógica o de mera retórica ${ }^{2}$. Ello es así aun si se trata de lo que podría calificarse de una política puramente negativa, por ejemplo, una política de radical aislacionismo como la que intentó en algún sentido Chile entre 1973 y 1990, asumiendo conscientemente una condición de país paria impuesta exógenamente ${ }^{3}$. Obviamente, se pueden imaginar coaliciones menores, con sentidos positivos

2 En el caso de Chile, ciertamente se puede identificar un uso retórico de apelaciones a la región y lo regional, y ello es común al conjunto de los países. Inversamente a lo que sucede hoy con los miembros de ALBA, Chile no emplea propuestas de políticas con referentes regionales insinceros, que en realidad constituyen artefactos demagógicos orientados tanto a usos políticos internos como hacia fuera, y ello permite prescindir de esta variedad «espuria» de políticas.

3 Obviamente, una política de aislacionismo absoluto respecto de los países de la región es imposible, en razón de que no se puede prescindir de los vecinos. o negativos, esto es de cooperación entre un subconjunto de países o de concertación contra un tercero externo a la coalición, en que el liderazgo en la formación de la coalición lo tenga alguno de los países medianos o menores, pero por definición lo que implementen no será una política regional. A la vez, no es inconcebible que un país mediano o una coalición de ellos, que podría incluir uno o más países menores, se propongan liderar la formación de una coalición más inclusiva, cuya meta sea la identificación e implementación de una política regional, pero su éxito va a depender de que logre incluir también a Brasil en esa coalición, y al menos desde el momento de la inclusión el liderazgo será compartido con este último. Lo predecible es que esa incorporación implicará que Brasil asuma el liderazgo de la coalición. No obstante que escenarios de ese tipo son lógicamente posibles, no parece observarse casos en que ellos se hayan hecho efectivos.

Este más que acentuado desequilibrio estructural del contexto geopolítico suramericano, unido a una política exterior brasileña sistemáticamente reticente a asumir un liderazgo regional, política vigente probablemente hasta la segunda presidencia de Cardoso, es lo que hacía particularmente irrelevante ocuparse del tema de una política chilena con un referente regional, irrelevancia susceptible de extrapolarse al resto de los países suramericanos. Es el cambio en la política exterior brasileña lo que ha convertido al tema en asunto relevante y prioritario en la agenda de 
la política exterior chilena de la última década.

\section{B. Desequilibrio,}

DESCONFIANZA Y PREDOMINIO

DE COMPORTAMIENTOS

REACTIVO-DEFENSIVOS, BÚSQUEDA DE UN EQUILIBRIO

El desequilibrio estructural que caracteriza a la región genera algunas consecuencias que afectan tanto a Chile como a los restantes países suramericanos, que conviene destacar.

Como regla general, salvo en ámbitos bilaterales o en contextos coalicionales de tamaño pequeño en los que todos los miembros de la coalición poseen una jerarquía similar, es altamente improbable que los países medianos o menores puedan desplegar eficazmente políticas exteriores proactivas (Flisfisch, 2010). Por consiguiente, en contextos regionales, globales o multilaterales, la regla general es que respecto de estos países se observarán políticas exteriores cuya naturaleza es reactiva: la iniciativa en los más diversos dominios en cuanto a formular y hacer explícitas políticas corre por cuenta de actores cuyo estatus es de países mayores (potencias mayores, potencias menores, potencias «emergentes», en suma, países «imprescindibles»); por el contrario, los países medianos y menores reaccionan a esas iniciativas y su despliegue mediante políticas sujetas a un conjunto significativo de restricciones, impuestas precisamente por las iniciativas de los países mayores.
De acuerdo con las proposiciones anteriores, la política exterior chilena, entendida como un haz de políticas específicas y, cuando ello ha sido afortunadamente así, todo este conjunto orientado por una gran estrategia, hay que comprenderla como fundamentalmente reactiva, salvo en contextos de relaciones bilaterales, particularmente relaciones vecinales y para-vecinales, $\mathrm{o}$ subrregionales y subsectoriales muy circunscritas. En el caso específico de una política suramericana ello implica que en la medida en que no exista un liderazgo regional que despliegue explícitamente una política con claros referentes suramericanos, no se observarán reacciones chilenas que ameriten calificarse en términos de una política exterior de Chile referida a Suramérica, y esto fue exactamente lo que sucedió durante las últimas cuatro a cinco décadas ${ }^{4}$. En el mismo sentido, el abandono por Brasil de lo que se podría caracterizar como una política aislacionista secular que rechaza explícitamente asumir un liderazgo regional en razón de expectativas sobre los potenciales costos que podría implicar asumirlo, especialmente respecto al riesgo de deterioro de las relaciones bilaterales por la difusión de un clima de desconfianza derivado de la aspiración a ese liderazgo, una vez manifiesta y puesta en obra, es el hecho que precipita una reacción chilena en búsqueda de configurar y desplegar

4 La naturaleza cabal de las iniciativas de integración, particularmente durante la séptima década del siglo pasado, es algo que aún no ha sido estudiado en profundidad. 
una política exterior suramericana. Lo que acontece en este ámbito durante los últimos diez años viene impuesto por la fuerza de las cosas: ha sido un asunto de necesidad y de obediencia al conjunto de restricciones derivadas en su mayoría del carácter que Brasil ha buscado imprimir al desarrollo de su liderazgo.

El hecho de que la naturaleza reactiva de la política exterior constituya la regla general en el caso de un país como Chile, situación que comparte con los otros diez países que además de Brasil conforman la región, no prejuzga sobre otros rasgos que puedan caracterizarla. Específicamente, ello no implica políticas necesariamente defensivas. En la medida en que aquello respecto de lo cual se reacciona no encierra connotaciones amenazadoras, o tal como es percibida la situación generada por la iniciativa proactiva de un tercero, ella conforma algo mucho más cercano a un juego de suma variable que a uno de suma nula, $o$ las expectativas que razonablemente se pueden sustentar sobre posibles desenlaces es que se pueden esperar beneficios importantes versus costos menores, cabe predecir reacciones positivas, orientadas por componentes importantes de confianza. Contrariamente, en la medida en que las expectativas y percepciones apunten a amenazas, riesgos y costos potenciales altos, se tendrán políticas reactivas defensivas, o reactivo-defensivas, basadas en niveles significativos de temor y desconfianza.

Desde el punto de vista chileno, la posibilidad de un liderazgo brasileño en la región se ha asociado en las últimas décadas a un componente de desconfianza, basado en expectativas difusas de amenazas y riesgos diversos. Por ejemplo, está el temor endémico a que la asunción por Brasil de un liderazgo implicaría un despliegue de aspiraciones hegemónicas en la región, sin demasiada claridad respecto de en qué consistirían esas aspiraciones. Curiosamente, es la percepción de la existencia de ese mismo temor en los países sudamericanos lo que constituiría una de las motivaciones principales de lo que podría llamarse política de abstención brasileña respecto de América del Sur. Según un observador brasileño privilegiado de la política exterior de su Cancillería ${ }^{5}$ (Vilalva, 2010), "durante muchos años se discutió si valía la pena o no asumir abiertamente la idea de un liderazgo en la región (puesto que se)... creía que esto podría sacar del armario los antiguos fantasmas de que Brasil era una potencia hegemónica y otros adjetivos similares».

Es justo destacar que esa desconfianza no fue simplemente producto de una suerte de paranoia típica de un país mediano al enfrentar las posibilidades de protagonismo de un tercero del que lo distancian asimetrías profundas. Observando a vuelo de pájaro la historia de los últimos sesenta años, se destacan al menos dos hechos que confirieron carne a esos "antiguos fantasmas» a que se refiere la cita anterior. Por una parte, es indudable la vigencia y difusión que adquirió durante los años sesenta y setenta

Mario Vilalva, Embajador del Brasil en Chile desde agosto del 2006 
del siglo pasado la noción de un subimperialismo brasileño, complementario con la hegemonía estadounidense sobre la región, asociada a las políticas y posicionamientos de los gobiernos militares brasileños de la época.

Por otra, se tienen elaboraciones político-intelectuales de izquierda, no muy alejadas de algunos protagonistas oficiales de la política exterior brasileña y bastante más recientes, con raíces en paradigmas marxistas y dependentistas, que avizoraron para Brasil una posición regional hegemónica en el contexto de un bloque sudamericano económicamente autosuficiente y acentuadamente estatista, caracterizado por una división del trabajo con un centro hegemónico industrializado -Brasil- y una periferia compuesta del resto de los países, en el rol de proveedores de materias primas e insumos para la industria del país central. Adicionalmente, este bloque sudamericano se posicionaría de manera antagónica al imperialismo norteamericano, identificado como enemigo principal. Obviamente, es el tipo de especulaciones con resonancias positivas en lo que podría denominarse de mentalidad ALBA.

A estas constelaciones de ideas, calificables de imaginarios sin mayor anclaje en la realidad y que parecen haber logrado solo una efectividad política menos que menor, hay que añadir, como elementos generadores de desconfianza, el temor difuso frente a asimetrías y desequilibrios más que pronunciados, que de por sí aconsejan políticas cautelosas y prudentes. Todo ello explica que frente al giro de Brasil hacia una política sudamericana caracterizada por su aspiración a un liderazgo regional manifiesto, durante una primera etapa la política chilena hacia Sudamérica haya asumido una naturaleza fundamentalmente reactivo-defensiva.

Otra dimensión que se asocia a la lógica y al movimiento de la geopolítica sudamericana, y que tiene un nítido impacto en la política exterior chilena, son los esfuerzos por sustituir el referente regional sudamericano por un referente latinoamericano más amplio, que incluya a México, esfuerzos que se reiteran irregularmente en el tiempo. La motivación detrás de estos esfuerzos es obvia: en un contexto latinoamericano la envergadura de México reintroduce una posibilidad de equilibrio a partir de una suerte de estructura bipolar, que ampliaría significativamente los grados de libertad en movimientos estratégicos de los países medianos y menores. Adicionalmente, hay que destacar que en estos esfuerzos por "latinoamericanizar» los contextos y políticas no es ajeno México como protagonista. De hecho, es una conjetura razonable sostener que lo que podría denominarse como la cuestión brasileña es un asunto que preocupa y está en la agenda tanto de México como de los restantes once países sudamericanos. Puesto de otra manera, para México el escenario de una hegemonía regional brasileña es tan poco deseable como para esos once países, y por lo tanto una iniciativa de liderazgo brasileño es algo a lo que hay que reaccionar con cautela y prudencia. 
Hay dos iniciativas contemporáneas a las que se puede conferir ese sentido. Una es la Cumbre de América Latina y el Caribe (CALC), concebida de manera más bien laxa como un espacio informal de debate entre Jefas y Jefes de Estado y de Gobierno, inaugurada en Costa de Sahuipe, Brasil, en 2009, con una segunda reunión en Cancún a comienzos de 2010, reunión que respondió al nombre de Cumbre de la Unidad de América Latina y el Caribe, simultáneamente con una reunión del Grupo de Río en que Chile asumió la presidencia y secretaría pro témpore del Grupo para el bienio 2010-2011. Si bien CALC es una iniciativa brasileña, que puede interpretarse como una suerte de movimiento preventivo para neutralizar precisamente iniciativas mexicanas de «latinoamericanización» con un claro liderazgo mexicano, y por consiguiente evitar riesgos de debilitamiento de la Unión de Naciones Suramericanas (UNASUR), que constituye la apuesta central y la primerísima prioridad brasileña, lo cierto es que, al menos en un comienzo, México la asumió con entusiasmo, probablemente visualizando en ella una oportunidad para recobrar tiempo perdido e impedir quedar fuera del gran juego regional de los países del sur.

La otra iniciativa, esta vez nítidamente de origen mexicano, reside en la revitalización del Grupo de Río (GRío) y su reestructuración como instancia formal de concertación política, que descanse en un tratado constitutivo o instrumento jurídico formal, premunida de cierta organicidad y estructuras burocráticas. Esta era precisamente la propuesta que México había explorado para la reunión de Cancún de comienzos de 2010. En este caso, la rivalidad de la iniciativa con las posibilidades de consolidación de la UNASUR es manifiesta, independientemente de un componente simultáneo de rivalidad con la Organización de los Estados Americanos (OEA) y de los costos potenciales derivados de la exclusión de Canadá y Estados Unidos.

Para la política exterior chilena es más que razonable aprovechar todas las oportunidades que se abran en términos de una inclusión de México en el juego sudamericano, como también es razonable proponer y avanzar iniciativas que apunten a esa inclusión, y esta afirmación posee también validez para los restantes diez países distintos de Brasil. Desde 1990, la retórica gubernamental oficial chilena refleja cabalmente esta motivación. De estarse a esa retórica habría que concluir, según se insinuó más arriba, que Chile posee una política regional latinoamericana más que una política regional sudamericana. No obstante, estos esfuerzos por «latinoamericanizar» la política regional han sido por lo general infructuosos. Además, hay indicios suficientes como para conjeturar que el estatus de México como actor mayor en el contexto sudamericano, capaz de imponer un mayor equilibrio en el contexto regional y tal como ese estatus es visto por los restantes países, se ha debilitado significativamente en la última década. Por ejemplo, la recepción chilena en el 
2009 y comienzos del 2010 de la iniciativa mexicana de reestructurar el GRío fu simplemente contemporizadora y buscó congelar la situación argumentando la necesidad de no burocratizar ni rigidizar una instancia cuya utilidad reside precisamente en su flexibilidad. Una estrategia similar, aun cuando sería injusto hablar de una estrategia de postergación deliberada indefinida ${ }^{6}$, fue la adoptada respecto de una vigorización y progresos reales en el ámbito de la CALC, estrategia que probablemente ha sido la de la mayoría de los países. De hecho, si bien en la cumbre de Cancún de 2010, se decidió crear una Comunidad de Estados Latinoamericanos y Caribeños, la siguiente cumbre está contemplada para julio de 2011 y el único progreso que se advierte es un párrafo de la declaración final de la cumbre presidencial de la UNASUR de mayo de 2010 donde se manifiesta el deseo de que en la cumbre de la CALC del 2011 se avance en la concreción de esa Comunidad. En los dos casos, una condición que ha favorecido esas decisiones es precisamente esa imagen débil de México como actor principal o imprescindible.

Una conclusión que se sigue naturalmente de las características de la situación contemporánea es que esa imagen debilitada es producto de la emergencia del liderazgo brasileño. Ciertamente, es razonable pensar que ese hecho contribuye a ese debilitamiento. Pero hay también otras razones plausibles que podrían explicarlo.

6 Es decir, lo que connota la noción en inglés de «procrastination", de difícil traducción.
Una de esas razones complementarias es la desaparición de los elementos que en el pasado cimentaron el prestigio otorgado a México por parte importante de las elites sudamericanas. Entre ellos, la memoria de una revolución anti-oligárquica, «nacional-popular», con componentes sociales pioneros en la modernización de las ex colonias hispanas, asociada a la presencia más contemporánea de un nacionalismo anti-imperialista más que acentuado y la construcción de un Estado desarrollista que profundizó en sus políticas los componentes «nacional-populares» heredados de la revolución. Aun cuando dicho hoy ello sea cabalmente una herejía de incorrección política extrema, también se asoció a ese prestigio la notoria estabilidad política lograda por lo que podría llamarse de Régimen PRI, de modo de respetar las particularidades históricas, soslayando categorizaciones politológicas abstractas y generales. En un contexto de varias décadas signado por quiebres institucionales, inestabilidad política recurrente, dictaduras militares, gobiernos de bajo desempeño incapaces de enfrentar el agotamiento de estrategias de desarrollo, procesos de modernización incontrolados y fenómenos de represión política y social, la verdad es que tanto la estabilidad asociada a un régimen de partido hegemónico capaz de lograr movilización y apoyos masivos y virtualmente fusionarse con el estado nacional, como el tipo de políticas y la estrategia de desarrollo implementadas por ese régimen, adquirieron hasta un cierto perfume 
paradigmático en amplios sectores de elites, incluyendo establishments de las políticas exteriores. Hoy, esos componentes de un prestigio pasado fueron barridos por los vientos de liberalización, democratización y globalización.

Obviamente, también explica el debilitamiento la constelación de problemas que enfrenta hoy México, problemas que entre otros efectos han obligado a su política exterior a establecer prioridades distintas de las que implicaría un énfasis regional sudamericano, pero la visibilidad de estos factores más coyunturales no debería hacer perder de vista la existencia de dimensiones más estructurales, más permanentes, que desde el punto de vista de los procesos políticos y la economía política regionales sudamericanos afectan importantemente las posibilidades protagónicas mexicanas en la región. Clausurada la opción de una estrategia de desarrollo hacia adentro, con fuertes connotaciones autárquicas y anti-estadounidenses, la geopolítica y la geoeconomía mexicanas contemporáneas imponen restricciones severas a la orientación de su política exterior, de modo tal que, desde un punto de vista bastante objetivo y realista, lo regional sudamericano no solo pasa a ser una cuestión relativamente secundaria sino aun más, puede entrar en contradicción con el buen desempeño y éxito de unas políticas necesariamente orientadas hacia el Norte.

De este modo, para las políticas exteriores de los países sudamericanos, incluyendo Chile, es altamente probable que la opción de privilegiar a México como un actor capaz de generar una configuración estructural más equilibrada, un relativo balance de cara al liderazgo brasileño sea hoy una opción irreal. Para Chile, una política sudamericana tiene que partir del liderazgo brasileño emergente como dato duro y crucial y es ello lo que ha acontecido durante los últimos cinco años.

\section{UNASUR Y EL LIDERAZGO \\ BRASILEÑO: ETAPAS Y \\ TENSIONES DEL PROCESO}

De acuerdo con lo que señala Vilalva (Vilalva, 2010), la aspiración brasileña explícita a ejercer un liderazgo regional se remonta a la presidencia de Fernando Henrique Cardoso y cabe fecharla aproximadamente una década atrás. La decisión habría sido estrictamente presidencial y se concretó en una convocatoria a una cumbre presidencial sudamericana, celebrada en agosto del 2000 , focalizada en el tema de infraestructura, reunión a la que se asoció el nacimiento de la Iniciativa para la Integración de la Infraestructura Regional Suramericana (IIRSA). Según Vilalva, la decisión presidencial se tomó en términos de una relación relativamente tensa con la Cancillería brasileña: «Fernando Henrique se distanció tácticamente de Itamaraty y fue a buscar en otros Ministerios el apoyo que necesitaba para convocar a esa reunión. En Itamaraty, siempre estaba presente la idea de que una decisión como esa podría provocar más problemas que ventajas». 
Este origen permite destacar dos puntos que proyectan una sombra larga hacia todo el proceso posterior, que culminará con la creación de la UNASUR.

Uno es el contenido de la reunión. Hasta hoy impera en estas latitudes la noción de que el éxito del proceso de integración europea se debe entre otras cosas al acierto de haber sabido identificar en los orígenes un binomio sustantivo -carbón y acero- que posibilitó toda la fructífera dinámica posterior. La receta consistiría entonces en escoger una fórmula simple, en lo posible un binomio, preñada de las potencialidades del binomio europeo. La reunión del 2000 identificó un componente: el tema de la infraestructura. Cuatro años después, la presencia e insistencia protagónicas de Venezuela llevarían a identificar el segundo tema: la energía. Así devino sentido común reiterado en múltiples intervenciones de autoridades presidenciales y ministeriales, que infraestructura y energía deben jugar en América del Sur el rol del carbón y el acero en el proceso europeo. El supuesto, nunca puesto en discusión, de que un proceso de integración exitoso necesariamente descansa en una cooperación multinacional en actividades materiales de producción y distribución genera por otra parte un conjunto de expectativas sobre la base de las cuales se juzgan posteriormente los desarrollos que se obtienen, con las consiguientes evaluaciones negativas y frustraciones frente a los escasos avances obtenidos. Como se verá después, las actividades de la UNASUR han tendido a consolidar- se en términos de concertación política y coordinación y cooperación en los ámbitos de diversas políticas sectoriales, con resultados razonables en estas materias pero con progresos escasos y no muy promisorios en infraestructura y energía. Ello apunta a la conveniencia de no dejarse capturar por otras experiencias, y de poner en discusión el supuesto arriba referido.

El otro punto que vale la pena destacar es esa tensión o relación conflictiva entre la Presidencia, por una parte, y el establishment de la política exterior -Cancillería y burocracia diplomática- por la otra. Durante toda la década esa relación conflictiva tenderá a reproducirse en buena parte de los países, incluyendo Chile. Hacia el 2007, habrá cristalizado en la existencia de un «partido presidencial» pro UNASUR, que se esforzará por convertir en moneda corriente la noción de una diplomacia presidencial, opuesta a la diplomacia normal practicada por las Cancillerías y sus burocracias, evaluada por los núcleos de asesoría presidencial directa como un agente conservador, obstaculizador de un proceso de integración acelerado y comprensivo, que necesariamente implica algunos cambios radicales, por ejemplo en cuanto a debilitamiento de soberanía. Tanto esa relación conflictiva como las percepciones y visiones recíprocas de ambos conjuntos de agentes dominaron de manera soterrada y silenciosa todo el primer período de desarrollo de la iniciativa brasileña. De hecho, una vez tomada el 2004 en Cusco la decisión de crear una Comunidad Sudamericana 
de Naciones, y después de adoptarse el 2005 en Brasilia una agenda prioritaria y un plan de acción para progresar en la elaboración de un tratado constitutivo, se conformó también un grupo de trabajo de muy alto nivel ${ }^{7}$, integrado por asesores presidenciales, representantes directos de cada Jefa o Jefe de Estado y que teóricamente responderían sin intermediaciones a ellos, para que elaboraran los fundamentos doctrinarios o ideológicos y los rasgos fundamentales del tratado y la institucionalidad a que daría origen. En el contexto de la relación conflictiva esbozada, el informe de este grupo de trabajo fue finalmente procesado en reuniones de Cancilleres y de altos funcionarios, y la verdad es que su contribución principal hay que verla en los artículos 2 y 3 del tratado constitutivo suscrito en mayo del 2008 en Brasilia, que versan sobre el objetivo general y los objetivos específicos de la organización.

En cierto sentido, el desarrollo de los acontecimientos tiende a reflejar comparativamente el éxito de la «diplomacia normal» respecto de la «diplomacia presidencial», y de hecho en el período que va desde el 2007 a mayo del 2008, la interacción diplomática entre los países se localizó en el nivel de Cancilleres y altos funcionarios de cancillerías-Consejo de Delegadas y

En su etapa final, Argentina estuvo representada por su actual Presidenta; en el caso de Brasil, rotaron dos de los principales asesores directos del Presidente Lula en política exterior. La Presidenta Bachelet fue representada por un distinguido político, académico y diplomático de gran confianza suya.
Delegados en la institucionalidad de la UNASUR-, con una agenda que dio primera prioridad a la discusión de un proyecto de tratado constitutivo. No obstante, y siempre en el contexto de la tensión ya descrita, la «diplomacia presidencial» irrumpió el 2006 en la Cumbre Presidencial de Cochabamba, con efectos principalmente en lo que llegó a ser la retórica oficial de la organización, y con mayor impacto el 2007 en la Cumbre de Isla Margarita, donde una Venezuela protagónica, en una maniobra sorpresiva, además de lograr cambiar el nombre a Unión de Naciones Suramericanas, en ausencia de todo marco institucional obtuvo la creación de un Consejo Energético de Suramérica y un compromiso explícito de progresar aceleradamente en la preparación de un proyecto de tratado.

La evidencia de que se dispone apunta a un compromiso inicial más bien débil de Chile con las decisiones del 2004 y el 2005, adoptadas en Cusco y Brasilia respectivamente. Ello se explica en términos de la lógica reactivo-defensiva que viene naturalmente impuesta por la geopolítica que caracteriza la región, determinada por el estatus de Brasil, a la que se aludió más arriba. En una primera etapa, esa lógica se concretó en lo que podría llamarse una estrategia de dilación y congelamiento, por lo general empleada por países medianos frente a situaciones complejas que no ofrecen salidas claras y cuyo desarrollo es potencialmente riesgoso. Lo deseable es que en la medida de lo posible las cosas permanezcan en el 
estado en que están. En el caso de las decisiones del 2004 y el 2005, el ideal era que ellas se mantuvieran en un plano simplemente retórico, sin proyecciones importantes en cuanto a una efectividad mayor. Además de Chile, es razonable conjeturar que una estrategia similar fue puesta en obra en un comienzo por Colombia, Perú, el Ecuador de la época, Uruguay y Paraguay, y por la gran mayoría de las cancillerías y sus respectivas burocracias que estaban en condiciones de hacerlo.

No obstante, el impacto de tres factores llevaron a Chile a variar la estrategia practicada en un comienzo, girando hacia un curso de acción que sin dejar de ser defensivo-reactivo, obligó a una mucho mayor creatividad, compromiso y aun adopción de la iniciativa, tanto frente a Brasil como respecto de otros países.

El primero es el cambio de prioridades en la política exterior a partir del 2006, al asumir la Presidencia la Presidenta Bachelet. Como lo señala un documento oficial del período (Principios y prioridades de la política exterior de Chile, Gobierno de Chile, Ministerio de Relaciones Exteriores, 2007), "América Latina continuará siendo el área prioritaria de atención política, a partir de la cual se profundizarán cada vez más los lazos en otros ámbitos... Creemos que nuestra pertenencia a América Latina debe imprimir el sello de nuestra política exterior». A partir de esa prioridad, hecha explícita ya en el programa de gobierno de la Presidenta y reiterada en múltiples ocasiones y declaraciones oficiales, era imposible para la diplomacia chilena mantenerse en una estrategia de dilación y congelamiento, que en los hechos significaba muchas veces aparecer en posiciones de obstrucción frente al activismo acelerado de varios de los protagonistas del drama regional.

El segundo factor es la consolidación de la Alianza Bolivariana para la Américas (ALBA), impulsada por el Presidente Chávez a partir del 2001, inicialmente como alternativa al Área de Libre Comercio de las Américas (ALCA) propiciada por Estados Unidos. En un proceso que tiene como primer hito un acuerdo de cooperación entre Venezuela y Cuba el 2004, se van sucesivamente incorporando al acuerdo Bolivia el 2006, Nicaragua el 2007, Dominica y Honduras el 2008, y finalmente el 2009 Ecuador, San Vicente y las Granadinas y Antigua y Barbuda. Para los efectos de la evolución de la situación sudamericana, el núcleo duro que importa comprende a Venezuela, Bolivia y Ecuador, con una cercanía presidencial importante de Argentina a ese núcleo.

Bajo un nítido liderazgo venezolano, se desarrolló desde la época de la reunión de Cochabamba del 2006 una incesante presión para hacer avanzar y consolidar la UNASUR en términos de un modelo armónico con lo que podríamos llamar mentalidad ALBA, expresiva de liderazgos altamente personalizados, desarrollados en contextos internos caracterizados por una tendencia acentuada hacia una desinstitucionalización político-estatal y económica, a la que se 
asocian significativos grados de discrecionalidad presidencial, tendencia que es el resultado de políticas deliberadas orientadas a ese objetivo. La noción de diplomacia presidencial, a la que se hizo referencia anteriormente, obviamente es coherente con esta mentalidad. Paradójicamente, esa tendencia coexiste con un también acentuado esfuerzo por implementar políticas fuertemente estatistas en los más diversos ámbitos.

Según se mostró claramente a partir de la cumbre de Cochabamba el 2006, en términos de esta mentalidad ALBA el modelo deseable de organización para la UNASUR debería orientarse a conferir una institucionalidad a un bloque regional significativamente cerrado, capaz de desplegar políticas productivas y distributivas con un sentido anticapitalista, antagónico a la globalización, a los Estados Unidos y, en general, al mundo desarrollado.

Ese objetivo global perseguido por el componente ALBA de la coalición que procuraba conformar Brasil para llevarla en definitiva a constituirse como una organización formal, es un objetivo claramente contradictorio con la estrategia chilena de desarrollo, que descansa en una economía de mercado cabalmente institucionalizada, más que significativamente abierta, en una institucionalidad político-estatal también altamente institucionalizada, en una política exterior comercial de regionalismo abierto y pro globalización, y en el cultivo y fortalecimiento de relaciones con el primero y segundo mundos, incluyendo la prioridad otor- gada a los países caracterizados como de «mentalidad similar ${ }^{8}$ (Perspectivas, Proyecciones y Desafíos de la Política Exterior de Chile, Gobierno de Chile, Ministerio de Relaciones Exteriores).

Esa nítida contradicción entre un tipo de proyecto armónico con los intereses de Chile versus la clase de proyecto conveniente para la ideología e intereses del ALBA, planteó a la política exterior chilena un doble desafío. Por una parte, la situación exigía enfrentar y contener las iniciativas originadas en el componente ALBA de la coalición, esto es, exigía una estrategia en algún sentido negativa. Por la otra, la adopción de la prioridad latinoamericana requería un protagonismo también activo, pero ahora en un sentido positivo. La armonización de ambas orientaciones llevó a definir y poner en obra una estrategia de contención y contraproposición, esto es, una estrategia de contención de iniciativas no deseables desde el punto de vista chileno y de proposición de alternativas conformes con ese punto de vista, de modo de negociar y lograr desenlaces satisfactorios. Esta estrategia se mostró lo suficientemente efectiva como para contribuir sustancialmente a la conformación definitiva tanto de la institucionalidad de la organización como del sentido de sus actividades y políticas, todo ello sin perjudicar los intereses de Chile.

El tercer factor dice relación con los potenciales costos, especialmente políticos, que podría significar para Chile la

8 «Like-minded countries» 
autoexclusión de la iniciativa gatillada e impulsada por Brasil. La decisión de ser o no parte de una coalición como la que Brasil impulsó para construir una organización regional, y en definitiva esa era la disyuntiva que planteaba la iniciativa brasileña, tiene que ver no solo con los costos y beneficios que implica ser miembro activo de ella sino también con los costos y beneficios que puede implicar quedar fuera de la coalición. Frente a la estrategia desplegada por la mentalidad o componente ALBA de la coalición, la única opción para Chile no era poner en obra una estrategia activa de contención y contraproposición. Una estrategia alternativa habría consistido en asumir una posición periférica marginal, casi de mero observador, apostando a la ineficacia de las acciones realizadas y manteniéndose atentos a no dejarse capturar en situaciones que pudieran significar compromisos indeseables, estrategia que de hecho fue seguida en gran medida por Perú, Paraguay y Uruguay, como asimismo por la diplomacia argentina en la medida de lo posible. Pero en el fondo esa estrategia habría mostrado a Chile asumiendo una posición casi de antagonismo pasivo respecto del liderazgo brasileño, ciertamente con altos costos potenciales en lo inmediato y en tiempos más largos. La expectativa de esos costos políticos no podía llevar sino a desechar esa segunda alternativa y optar por ese involucramiento activo que significa una estrategia de contención y contraproposición.

\section{LAS REGLAS BÁSICAS DEL JUEGO}

Si bien no es del caso entrar a un comentario detallado del proceso de creación de la UNASUR en cuanto concreción de un liderazgo brasileño emergente, que va desde el 2006 hasta el 2009, de sus hitos y sus sucesivos desenlaces, vale la pena detenerse en los rasgos institucionales esenciales sobre los que descansa la conformación de la UNASUR, como asimismo analizar las restricciones que pesan sobre el tipo de políticas e iniciativas que son posibles para la organización.

En otras palabras, qué puede hacer sustantivamente la organización en términos de acciones colectivas de sus miembros, en un contexto de un número no menor de restricciones, de modo de identificar e implementar acciones y políticas que le otorguen sentido, evitando el estancamiento y una rápida decadencia.

La fuente primordial de las restricciones que operan sobre las potenciales actividades de la UNASUR reside en la más que significativa heterogeneidaddiversidad, en la retórica utilizada por la política chilena desde temprano-que caracteriza al conjunto de los doce países sudamericanos, esto es, diferencias en los más diversos ámbitos: nivel de desarrollo material, asimetrías de poder, estrategias de desarrollo nacional, mercado versus estatismo, principios e intereses en los que se basa la política exterior, políticas fiscales y financieras, políticas culturales, políticas judiciales, y probablemente varias otras. 
En este contexto de múltiples contradicciones entre países y grupos de países, el componente de contención de la política chilena la obligó a empujar con fuerza tres principios, reclamando para ellos la naturaleza de principios fundamentales sobre los que debe descansar la institucionalidad de la organización. Cabe advertir que en ambos casos se ha tratado de una política exitosa: los tres principios están consagrados en el tratado constitutivo de la organización.

El primero de ellos es el de la preservación de soberanía por cada Estado miembro, y en uno de los acápites del Preámbulo del instrumento jurídico mencionado se señala precisamente como uno de los principios rectores de la unión suramericana el irrestricto respeto a la soberanía de los Estados. Ello implica que no existe autoridad o instancia alguna en la institucionalidad organizacional que tenga un carácter supranacional, esto es, a la que se confiera la atribución de adoptar decisiones que sean vinculantes para todos los Estados miembros, independientemente de su aceptación o no aceptación por cada uno de ellos.

En realidad, este principio está en el interés de todos los miembros. En un contexto en que el conjunto de intereses comunes es significativamente más reducido que el de intereses en conflicto o potencialmente en conflicto, en ausencia de este principio la probabilidad para un miembro cualquiera de ser víctima de una imposición por la autoridad o instancia supranacional que sea contradictoria con sus intereses es una probabilidad alta. Este riesgo es lo suficientemente real aun para los países más poderosos. En efecto, el número de países miembros es lo suficientemente grande como para que la posibilidad de que un país poderoso enfrente una coalición mayoritaria tenga una probabilidad de actualización no menor.

El segundo principio es la expresión operativa del primero, en términos de la regla de decisión básica que impera en todas las instancias organizacionales, aplicable a todo tipo de materias y cuestiones. Esa regla es la regla de consenso, consagrada en el artículo 12 del tratado constitutivo. En esta materia, durante todo el período de deliberaciones sobre ese tratado -esto es, entre el 2006 y mayo del 2008- la política chilena convirtió la regla del consenso en una cuestión absolutamente intransable, aprovechando todas las oportunidades que se presentaron para insistir una y otra vez en su carácter absolutamente necesario para el éxito de la iniciativa brasileña.

Durante el corto tiempo de existencia de la organización, la vigencia en términos absolutos de la regla de consenso enfrentó una crisis temprana. El 2008, después de un infructuoso esfuerzo por obtener la designación de un con-nacional ex Presidente de la República como Secretario General de la UNASUR, propuesta que fracasó por desistimiento del propio candidato, el Presidente ecuatoriano propuso la candidatura a ese cargo del ex Presidente argentino Néstor Kirchner, nombramiento al que se opuso Uruguay en el contexto del litigio entre ambos países sobre las plantas uruguayas de celulosa. 
La tensión en torno a la candidatura y su potencial conflictivo duró hasta la reunión de jefes de Estado de comienzos de mayo del 2010, al levantar el veto a ella el nuevo Gobierno uruguayo y durante los dos años en cuestión hubo varios intentos por redefinir o relativizar la regla del consenso, que de haber tenido éxito habrían erosionado ciertamente su legitimidad. La política explícita chilena, a cargo de la presidencia pro témpore de la organización durante buena parte del período, fue la de rechazar esos intentos, pese a la necesidad de tener que apoyar, también de manera explícita, la candidatura Kirchner, entendiendo que en esta materia el pragmatismo significaba sólo el comienzo del fin, pragmatismo que en diversas situaciones obró como alternativa muy seductora. En una situación en que varios de los actores están habituados a la desinstitucionalización como estrategia de uso corriente, adoptar una posición pro mantención y reforzamiento de la institucionalidad no es tarea fácil, pero en términos de una coalición que incluía a Chile, Uruguay, Colombia, Perú y una actitud brasileña generalmente positiva, esa posición logró ser exitosa.

En aquellas situaciones en que la conflictividad es solo potencial y no hay todavía una estructuración de las posibilidades de desenlace en términos de una suerte de juego de suma nula o de alternativas polares excluyentes, la regla de consenso implica incentivos para la búsqueda, mediante la negociación, de soluciones o desenlaces razonablemente satisfactorios para el conjunto de los miembros, o en todo caso desenlaces que no signifiquen perjuicios o costos inaceptables para algunos de ellos. Por consiguiente, en este tipo de situaciones la regla del consenso es funcional a la preservación de un clima de relaciones entre los miembros al menos razonablemente satisfactorio.

En cambio, en situaciones polarizadas de conflicto abierto, con una estructuración que tiende a un juego de suma nula, o donde el desenlace preferido por la mayoría implica costos inaceptables para la minoría, la regla del consenso implica efectivamente un derecho a veto para la minoría, que puede aun consistir en uno solo de los miembros, que en gran medida fue lo que sucedió en el caso mencionado más arriba. Claramente, la utilización de este veto por la minoría solo puede aparecer en la percepción de los afectados por él como un caso patente de obstrucción ilegítima de iniciativas que pueden gozar de un respaldo bastante amplio. Por consiguiente, en estos casos, e inversamente respecto de lo que sucede en el primer tipo de situaciones, la regla de consenso es disfuncional a la preservación de un clima de relaciones mínimamente positivo. En este sentido, la regla del consenso constituye un riesgo para el desarrollo organizacional.

Al menos en la clase de contexto prevaleciente hacia los años 2006 y 2007 en términos del futuro predecible del desarrollo de la UNASUR, en la apreciación chilena la probabilidad de encontrarse en situaciones con desenlaces negativos para el país y donde Chile era minoría elevada. Por ejemplo, tener 
que enfrentar la iniciativa de creación del Banco del Sur, en su formulación original, contradictoria con el tipo de institucionalidad financiera preconizada por Chile. En ese sentido, desde el punto de vista chileno la regla del consenso era un mecanismo defensivo imprescindible. Pero por otra parte, utilizar el veto que implica esa regla estando en una posición minoritaria, como habría ocurrido con la iniciativa brasileña recién referida, trae la consecuencia cierta de un costo político alto, costo que puede elevarse exponencialmente en la medida en que esta clase de situaciones comienzan a repetirse con frecuencia. Por lo tanto, admitiendo la necesidad de una regla de consenso no relativizada, a la vez la conclusión era que se requería también un mecanismo que permitiera evitar la reproducción de esas situaciones que fuercen a emplear el veto que implica la regla del consenso.

El mecanismo identificado constituye el tercer principio básico sobre el que descansa la institucionalidad de la UNASUR está contenido en el artículo 13 del tratado constitutivo, y en su elaboración y adopción definitiva cupo un acentuado protagonismo a Chile. De manera sumaria, la regla es que un país puede concurrir con su consentimiento a la adopción por consenso de una decisión respecto de una propuesta de políticas comunes o de creación de instituciones, organizaciones o programas comunes, con la opción de eximirse de aplicar total o parcialmente la política adoptada por un plazo definido o indefinido, o de eximirse de participar en la institución, organización o programa que se crea. Ello posibilita a una minoría, que puede consistir de uno solo, evitar costos o perjuicios inaceptables a sus principios o intereses y simultáneamente evitar perjuicios igualmente inaceptables a la paz organizacional interna.

\section{E. LO SUSTANTIVO: ACCIONES POLÍTICAS COLECTIVAS}

La historia sudamericana proporciona evidencia suficiente como para avanzar la hipótesis de que, al igual que otras iniciativas que han aspirado a una proyección regional, el destino de la UNASUR es el estancamiento y la decadencia con la consiguiente pérdida de sentido. Su supervivencia y proyección dinámica hacia el futuro exigen una organización capaz de aparecer hoy como una agencia que desarrolla actividades útiles para el desarrollo de la región y que se va conformando como un posible actor en el dominio de la política internacional y ello en un contexto de restricciones ya reseñado, que comprende tanto los rasgos básicos de su institucionalidad como la constelación de oposiciones o contradicciones entre sus miembros. Uno de los dominios en que eso es posible es el de acciones políticas colectivas referidas a focos de riesgo o tensión dentro de la región.

Independientemente de las proyecciones más globales a las que aspira el liderazgo brasileño emergente, su concreción regional sudamericana exitosa es probablemente crucial para un buen 
desempeño más allá de la región. Por consiguiente, la región debería ser una primerísima prioridad para la política exterior brasileña. Al mismo tiempo, es difícil concebir una política regional exitosa que no adopte la forma de construir una gran coalición de todos progresivamente institucionalizada, que es precisamente la naturaleza de la UNASUR. La alternativa a esa política consistiría en algo así como procurar ejercer un liderazgo en cada uno de los diversos contextos definidos por las relaciones bilaterales posibles o en cada uno de los distintos contextos subregionales que se pueden identificar, y hay razones para concluir que esa alternativa conduciría al fracaso.

En efecto, partiendo de la premisa razonablemente obvia de que el ejercicio de un liderazgo supone un rol protagónico en la producción y preservación de determinados bienes colectivos que benefician a todos los miembros de la región y que ello implica intervenciones o acciones políticas en determinados tipos de situaciones que encierran riesgos para esos bienes colectivos, se puede conjeturar que para ser exitosas esas acciones o intervenciones requieren de la cooperación de un grupo importante de países. En otras palabras, pese a los acentuados desequilibrios geopolíticos que caracterizan a la región, una acción solitaria brasileña no sería eficaz, por ejemplo, para neutralizar focos de riesgo que pudieran afectar la seguridad regional. En cambio, la gran coalición que es la UNASUR sí proporciona un contexto adecuado para la adopción e implemen- tación de iniciativas eficaces en la clase de situaciones que producen esos focos.

Un buen ejemplo de lo anteriormente señalado es el conjunto de acciones adoptadas con miras a la superación de la crisis interna boliviana en 2008 . Tal como se estaba desarrollando a comienzos de la segunda mitad de ese año la situación política en Bolivia amenazaba con transitar a un desenlace catastrófico. En el peor de los escenarios ese desenlace asumía la forma de una guerra civil y la probabilidad de ese escenario no era menor. Claramente, un escenario de conflicto armado en Bolivia habría constituido un escenario de riesgo mayor para el conjunto de la región, entre otras cosas, con posibilidades efectivas de un escalamiento que incluyera rápidamente a otros países como actores.

Tanto el desarrollo de la crisis como las modalidades adoptadas para superarla avalan lo afirmado anteriormente: el liderazgo brasileño es una condición contextual necesaria para el despliegue de una acción colectiva eficaz, pero no es suficiente. De hecho, aun cuando el punto pueda ser objeto de debates académicos posteriores, la iniciativa de convocar a una reunión extraordinaria, de emergencia, de Jefes de Estado de la UNASUR, realizada en Santiago de Chile el 15 de septiembre del 2008, fue una iniciativa de la Presidenta chilena, que en ese momento ejercía la presidencia pro témpore de la organización. La reunión posibilitó identificar y legitimar las modalidades de la gestión internacional posterior, a la vez que selló un 
fuerte compromiso de los países de la región con la preservación de la institucionalidad democrática.

No obstante, la iniciativa chilena no habría sido posible ni tampoco habría tenido la eficacia que mostró la gestión posterior en la que el protagonismo chileno fue muy acentuado, en un contexto del que hubiera estado ausente el liderazgo brasileño. El tipo de acción colectiva que demanda la clase de situaciones como lo fue la crisis boliviana del 2008 es eminentemente cooperativa, con grados diversos de protagonismo de los distintos actores, pero en última instancia descansa en el liderazgo brasileño.

Un contraste útil con esa crisis lo proporciona la situación provocada por el golpe de Estado en Honduras el 2009. La evolución de la situación, su temprano estancamiento, el cuestionamiento de la legitimidad del desenlace de hecho que permanece hasta hoy, todo ello habla no de insuficiencias del liderazgo brasileño y de ineficacia de una postura común a todos los miembros de la UNASUR, sino simplemente de un contexto geopolítico muy distinto del sudamericano. Lo que es eficaz en América del Sur, incluyendo el liderazgo brasileño y la coalición razonablemente cooperativa que es la UNASUR, no lo es en el contexto de un conglomerado que termina incluyendo a los países del Caribe y a los Estados Unidos. Ello permite concluir, además, que una absorción de la UNASUR en referentes como el Grupo de Río o CALC ciertamente sería negativa e implicaría volver al punto de partida en el ámbito regional sudamericano.

\section{F. Lo SUSTANTIVO: COORDINACIÓN DE POLÍTICAS SECTORIALES}

La mantención de una dinámica organizacional al menos suficiente para evitar el estancamiento no puede descansar solo en el desempeño por la UNASUR de ese rol de agente colectivo que despliega acciones e iniciativas frente a situaciones de crisis o focos de riesgo con potenciales alcances regionales, entre otras cosas porque no se trata de cuestiones provistas de una continuidad temporal que otorguen sentido a una coalición que busca permanencia a través de una progresiva institucionalización.

En ese contexto de heterogeneidad y conflictividad de intereses esbozado anteriormente, no ha sido fácil dar con tipos de actividad colectiva -algo así como una misión organizacional razonablemente clara- que permitan avanzar en esa institucionalización, dotándola simultáneamente de un mínimo sentido compartido.

Como se señaló más arriba, la propuesta original consideraba dos dominios productivos -primero infraestructura y luego también energía-, binomio que se suponía podía jugar el mismo papel que el carbón y el acero en los orígenes del proceso de integración europea.

El objetivo de progresar en infraestructura condujo a IIRSA, que finalmente 
fue reconvertida en un Consejo de Infraestructura y Planeamiento, al que se asocia un Grupo de Trabajo que ha concluido recién en 2010 un proyecto de estatuto y de reglamento para su funcionamiento, que debería ser aprobado por un consejo de ministros durante el año.

El tema de infraestructura y su expresión orgánica en IIRSA, fue vigorosamente apoyado por países como Brasil, Colombia y Chile, pero encontró actitudes hostiles, concretadas en una cabal estrategia de contención en miembros como Bolivia y Venezuela, fundadas en una apreciación negativa del objetivo de progresar en una infraestructura vial de interconexión regional inspirada en una concepción de modernización económica. De acuerdo a la clase de mentalidad opuesta a la IIRSA -en esa mentalidad, el equivalente contemporáneo de las "venas abiertas» de la visión dependentista de los años sesenta y setenta del siglo pasado-y la concepción que la inspira, a lo que se debería aspirar es a redes y caminos que acerquen a los pueblos y no que conecten mercados en una economía crecientemente globalizada. Adicionalmente, en esa concepción la IIRSA es también fuente potencial de daños tanto ecológicos como a pequeñas comunidades impactadas por las nuevas redes viales. Es esta colisión de intereses y visiones, que ha enfrentado una aspiración a la modernización económica en sentido clásico y una concepción ecológico-tradicional anti capitalista y anti globalización, la que explica la evolución más que mortecina del tema en el contexto de la UNASUR.

En el caso de la energía, el impulso original provino de Venezuela, que al inicio de la cumbre presidencial del 2007 en Isla Margarita, Venezuela, en una reunión previa informal no contemplada en la agenda, obtuvo un acuerdo para crear un Consejo Energético Suramericano y un Grupo de Trabajo asociado a él. La misión de ese Consejo era elaborar en plazos más que breves un plan de integración energética para la región, integración en la que jugaría un rol central y protagónico Venezuela y su petróleo, a partir de una apreciación acentuadamente voluntarista de las posibilidades de esa integración. Ese impulso encontró una respuesta chilena negativa, apoyada por otros países, asociada a la correspondiente contrapropuesta: orientar los esfuerzos a acordar un tratado energético sudamericano, como instrumento cuyo sentido básico sea el de otorgar certeza y seguridad jurídica a la provisión de energía, particularmente para los países más vulnerables en esta materia. Nuevamente, la colisión de intereses y visiones se tradujo en el empleo recíproco de maniobras dilatorias y estancamientos. Actualmente, hay acordada una estructura -es decir, un temario- para un tratado, con la expectativa de algún resultado hacia el 2011. Razonablemente, las expectativas que se pueden forjar sobre progresos en la materia son negativas.

La necesidad de identificar para la UNASUR tareas permanentes sustantivas, 
de modo de asegurar su proyección en el tiempo, se planteó con fuerza para la presidencia pro témpore chilena en el período del 2008 al 2009. El relativo fracaso con infraestructura y energía posibilitó extraer una lección. En efecto, lo que hay de común en ambos casos es que se trata de proyectos globales o programas de gran escala, que contienen un número importante de proyectos específicos, que implican inversiones mayores asociadas a costos financieros muy altos, y según se vio en un contexto de colisión de intereses económicos, políticos y también intereses ideales vinculados a imágenes del orden deseable de vida social y otros de naturaleza similar. Por consiguiente, parecía razonable buscar ámbitos de actividad organizacional que carecieran de esas características.

Varias experiencias desarrolladas en el MERCOSUR mostraban que actividades de cooperación y coordinación en políticas sectoriales como políticas de salud o políticas sociales podían ser viables precisamente al no involucrar proyectos de gran escala, que supongan inversiones importantes, y al insertarse en contextos ideológicamente más bien pacíficos. Por otra parte, ello era coherente con los objetivos básicos de gobierno del cuadrienio Bachelet.

Con esa experiencia en el trasfondo, entre el 2008 y el 2009 se desarrolló una auténtica política de creación de consejos, que comenzó con un Consejo de Desarrollo Social y un Consejo de Salud, creaciones que gatillaron una generosa oferta de creación de nuevos consejos: Consejo de Educación, Cultura, Ciencia,
Tecnología e Innovación, Consejo de Lucha contra el Narcotráfico (vuelto a bautizar en mayo de 2010 como Consejo Suramericano sobre el Problema Mundial de las Drogas), Consejo de Defensa Suramericano, más dos Grupos de Trabajo: Grupo de Trabajo sobre Integración Financiera, y Grupo de Trabajo sobre Mecanismos de Solución de Controversias en Materia de Inversiones.

Los dos grupos de trabajo mencionados al final, cuya orientación responde a posicionamientos afines a la mentalidad ALBA, con alta probabilidad no experimentarán desarrollos importantes y se estancarán al ser contradictorios con políticas económicas permanentes de países como Chile, Perú, Colombia, Uruguay y Brasil. El Consejo de Desarrollo Social, una propuesta chilena, presuponía una secretaría técnica radicada en la Comisión Económica para América Latina y el Caribe (CEPAL), encontró una posición negativa en Venezuela, en cuya visión CEPAL es una encarnación doctrinaria del neoliberalismo. Por otra parte, es un consejo que requiere de una secretaría técnica de gran calidad y hasta comienzos del 2010 no existían alternativas reales a la CEPAL. En la medida en que no se identifique una secretaría adecuada, es previsible un desenlace de estancamiento.

El Consejo de Educación y sectores afines nació a partir de una propuesta peruana, y si bien no presenta un dinamismo significativo hasta ahora, su éxito depende del compromiso que la política del Perú adopte en los próximos años respecto de la UNASUR en su glo- 
balidad. Luego, en el rubro de los casos con un destino hasta hoy relativamente incierto, hay que incluir el recientemente rebautizado consejo sobre drogas y narcotráfico. Obviamente, el compromiso de Chile y países afines como Colombia, Perú y Uruguay está sujeto a la condición de que tanto la arquitectura como la misión y funciones de un consejo semejante no entren en contradicción con la articulación de agencias y políticas hoy existentes, particularmente en términos de la cooperación internacional en la que los Estados Unidos juegan un rol crucial, y ciertamente propuestas contradictorias con lo que hoy existe pueden ser seductoras en determinadas coyunturas para la política boliviana. No obstante, un consejo semejante radicado en la UNASUR puede ser precisamente funcional, de manera indirecta, a la operación del sistema hoy establecido y en funcionamiento al facilitar triangulaciones que provean de legitimidad a políticas e iniciativas que simplemente no las tendrían en la medida en que el agente que aparezca primordialmente empujándolas sea Estados Unidos y agencias estadounidenses como la DEA. Una política y estrategias inteligentes orientadas en ese sentido podrían convertir ese consejo en un agente valioso, que agregue valor a la lucha contra el narcotráfico.

Tanto en el caso del sector de salud como en el de defensa, ambos consejos han sido razonablemente exitosos, pero por razones bien distintas.

El Consejo de Salud propuesto por Chile, además de contar con un apoyo efectivo de mandatarios como la presidenta chilena y el anterior presidente uruguayo, ambos médicos de profesión, descansó desde su origen en una experiencia exitosa en el contexto del MERCOSUR, en redes regionales muy densas de profesionales expertos en salud pública, en experiencias exitosas de cooperación de sectores de salud inclusivas de dos o más países y en el apoyo de la Organización Mundial de la Salud (OMS) como secretaría técnica, que inversamente al caso de CEPAL goza de una imagen de neutralidad y objetividad técnico-científica. La experiencia de este consejo posibilita dos inferencias. Por una parte, identifica un tipo de condiciones favorables que, de existir, aconsejan explotarlas para desarrollar iniciativas que probablemente serán exitosas en tiempos cortos, lo cual puede ser crucial para una supervivencia dinámica de la UNASUR. Por otra, indica que cuando esas condiciones no existen o bien es un error desarrollar iniciativas que con alta probabilidad fracasarán, debilitando la organización y su imagen, o bien se requiere de apuestas de plazos más largos, que posibiliten precisamente crear esas condiciones.

En el caso del Consejo de Defensa, en gran medida su éxito viene determinado porque la iniciativa fue brasileña y el compromiso de Brasil con su supervivencia y consolidación ha sido permanente, compromiso apoyado además por países como Chile. Ello permitió superar, en diversas reuniones durante el 2009 y comienzos del 2010, la fuerte tensión que suscitó la decisión colombiana de autorizar la instalación de 
bases militares con presencia estadounidense. Ello demuestra que en la medida en que hay dimensiones políticas con connotaciones conflictivas, el éxito de una iniciativa necesariamente descansa en un compromiso con ella del liderazgo brasileño, sin perjuicio de que Brasil requiera adicionalmente del apoyo de una coalición de algunos de los otros países. De los doce países de la región, solo Brasil es capaz de movilizar una coalición que neutralice las estrategias de contención de quienes se oponen a la iniciativa. Por el contrario, para que un país despliegue exitosamente estrategias de contención necesita la abstención de Brasil, o su apoyo, y ese ha sido precisamente el caso de los éxitos chilenos en sus estrategias de contención.

\section{G. A MANERA DE CONCLUSIÓN: EXPECTATIVAS PARA EL FUTURO PRÓXIMO}

Hace una década era quizás difícil visualizar que la emergencia de un liderazgo brasileño era algo probable, que esa emergencia adoptaría como forma o modalidad prioritaria una presencia regional activa expresada en acciones fundacionales como la creación de una organización política regional, y que ello implicaría, más que una condición de posibilidad de una política sudamericana para un país como Chile, la necesidad de identificar e implementar una política con ese carácter.

Ciertamente, la organización no es algo hoy consolidada, como lo demues- tra el hecho de que a comienzos de mayo del 2010 el tratado constitutivo había sido ratificado por cuatro países y por consiguiente se pueden tener dudas legítimas sobre su destino. De acuerdo con lo afirmado ya de manera reiterada, es relativamente obvio que ese destino depende muy principalmente de cuál sea la política sudamericana brasileña durante el próximo quinquenio bajo una nueva presidencia, y bastante menos de lo que hagan los otros once países.

En el caso de la política sudamericana chilena, lo anterior implica que el análisis debe atender menos a las características intrínsecas en política exterior de la presidencia Piñera y de las fuerzas políticas que lo apoyan, y mucho más a los desarrollos que tengan lugar en Brasil.

Las orientaciones en política exterior "connaturales» a las fuerzas políticas de derecha chilenas tienden a colocar prioridad en las relaciones bilaterales vecinales, en relaciones con «países afines» del primer mundo y en las relaciones comerciales con el Asia y el sudeste asiático. Respecto de América del Sur, el sentido común de derecha se inclinaría, en la medida de lo posible, por una política que implicara las menores y más débiles relaciones, dentro del ámbito de lo que la necesidad impone. De hecho, siendo oposición su reacción a las iniciativas de asociación planteadas durante los últimos diez años ha sido negativa, pese a ser iniciativas lideradas por Brasil, como lo demuestra la votación sobre la ratificación del tratado constitutivo de la UNASUR en la Cámara de Dipu- 
tados, y el estancamiento posterior de ese proceso en la Comisión respectiva del Senado. No obstante, ser Gobierno hace una diferencia, como lo prueba la continuidad respecto de la política chilena en materia sudamericana exhibida por el Presidente Piñera y la Cancillería chilena durante los primeros meses del 2010. En definitiva, solo cambiará esa política si se producen giros en la política sudamericana de Brasil.

$\mathrm{Al}$ mismo tiempo, el desenlace de la elección presidencial en Brasil parece garantizar una continuidad más que significativa en la política brasileña hacia América del Sur. En un contexto regional sudamericano de un más que acentuado y personalizado presidencialismo las figuras presidenciales constituyen una variable que explica en medida no menor el éxito o el fracaso de los movimientos que implementan una política exterior. Ello también tiene validez para Brasil, en su esfuerzo por robustecer un liderazgo regional sudamericano.

En ese sentido, la figura del actual presidente brasileño da cuenta de manera importante del éxito de su política exterior. Además del carisma y otras características personales -calidez, talento político, orígenes populares y sindicales, etc.-, hay que destacar su capacidad de proyectar una imagen ideológico-programática y sensibilidades políticas que le han posibilitado construir vínculos de afinidad con los mandatarios y mentalidades «de izquierda» en la región, consolidando con ellos relaciones razonablemente permanentes que evitan la adversarie- dad o la enemistad abierta. Todo ello independientemente de su política hacia el resto del mundo o hacia los asuntos internos, que sería difícil calificar «de izquierda», en términos del significado de la noción para, por ejemplo, la mentalidad ALBA. Así, la base objetiva de poder de Brasil, condición necesaria de su éxito en la región, ha interactuado importantemente con la figura política proyectada por Lula en el manejo de las relaciones con los otros mandatarios. Una figura presidencial del mismo color, que además con alta probabilidad será apoyada por el propio Lula y los actuales asesores de su entorno, con una alta probabilidad dará continuidad a la situación existente hoy, la cual más que plausiblemente se verá reforzada por el deceso del ex presidente Kirchner, dando a la política brasileña mayores grados de libertad en la consolidación de una arquitectura flexible y pragmática para la UNASUR.

En ese escenario, la gran estrategia de Chile sigue enfrentando la necesidad de otorgar una prioridad relevante a una política regional sudamericana, que sin perjuicio de privilegiar en el caso de Brasil el robustecimiento de la relación bilateral, y de focalizar un cierto interés en sub coaliciones dentro de la región -por ejemplo, el así bautizado Arco del Pacífico-, tiene que seguir operando con pocos grados de libertad importantes en el contexto de la UNASUR, practicando allí una política que necesariamente lo es bastante más que una política de mera presencia. 
ÁNGEL FLISFISCH • La política exterior chilena y América del Sur

\section{REFERENCIAS}

Fernández, Mariano (2010), «América Latina: Su integración, prioridad en la política exterior de Chile», en El Mundo desde el Sur. Voces de Chile en Política Exterior, Gobierno de Chile, Ministerio de Relaciones Exteriores

FLISFISCH, Angel (2010), «Las razones del compromiso de Chile con UNASUR", en El Mundo desde el Sur. Voces de Chile en Política Exterior, Gobierno de Chile, Ministerio de Relaciones Exteriores

Flisfisch, Angel (2010), «La necesidad de paradigmas adecuados a los diversos tipos de realidades nacionales», en Relaciones Internacionales y Renovación del Pensamiento, Leiva Lavalle Patricio (ed),
Instituto Latinoamericano de Relaciones Internacionales (Universidad Miguel de Cervantes), Institut d'Estudis Humanistics Miquel Coll i Alerton

Gobierno de Chile, Ministerio de Relaciones Exteriores (2007), Principios y Prioridades de la Política Exterior de Chile Gobierno de Chile, Ministerio de Relaciones Exteriores (2010), Perspectivas, Proyecciones y Desafíos de la Política Exterior de Chile

Vilalva Mario (2010), «La inserción de Brasil en América del Sur y en el nuevo orden internacional», en Relaciones Internacionales y Renovación del Pensamiento, Leiva Lavalle Patricio (ed), Instituto Latinoamericano de Relaciones Internacionales (Universidad Miguel de Cervantes), Institut dEstudis Miquel Coll i Alerton 